\title{
Enlarged Craniotomy with Membranectomy for Treatment of Completely Organized Chronic Subdural Hematoma: A Case Report and Literature Review
}

\author{
Xiao-Yong Shi \\ Zhejiang Hospital \\ Jin-Xia Zhang ( $\nabla$ 495777618@qq.com ) \\ Dingqiao Hospital \\ Zhu-Xiao Tang \\ Zhejiang Hospital \\ Hu Sun \\ Zhejiang Hospital \\ Zheng Shen \\ Zhejiang Hospital
}

\section{Case report}

Keywords: craniotomy, chronic subdural hematoma, membranectomy, Organized

Posted Date: July 8th, 2020

DOI: https://doi.org/10.21203/rs.3.rs-35500/v1

License: (c) (i) This work is licensed under a Creative Commons Attribution 4.0 International License.

Read Full License 


\section{Abstract}

Background Chronic subdural hematoma(CSDH) is a common condition in the elderly which can be treated by burr hole trephination and drainage. But completely organized chronic subdural hematoma $(\mathrm{OCSH})$ is rare which cannot be cured by this technique, only treated by enlarged craniotomy and membranectomy.

Case Presentation A 74-year old man admitted to hospital for loss of consciousness for one hour following a car accident. Cranial computed tomography (CT) showed a large mixed density hematoma on the left, acute subdural hematoma, cerebral contusion and subarachnoid hemorrhage. A left standard large craniotomy was performed. A large and completely OCSH with no liquid component was found during surgery, at the same time, we found no obvious adhesions between the inner membrane and the brain tissue, which was easy to separate and finally removed completely.

Conclusion Craniotomy with membranectomy is a feasible method for treating completely OCSH.

\section{Introduction}

Chronic subdural hematoma is a common condition in the elderly which can be treated by burr hole trephination and drainage. We report a case of CSDH with no liquid component between the membranes, which was completely organized and treated by craniotomy with membranectomy.

\section{Case Report}

The patient was a 74-year old man admitted to hospital for loss of consciousness for one hour following a car accident. CT showed right temporal fracture and epidural hematoma, multiple cerebral contusions and lacerations, subarachnoid hemorrhage, huge hematoma with mixed density on the left, and acute subdural hematoma (Figs. 1 and 2). Standard large bone flap craniotomy on the left side revealed a large, fully OCSH, ellipsoid in shape, and about $12 \mathrm{~cm}$ long, $10 \mathrm{~cm}$ wide and $3 \mathrm{~cm}$ thick. The wall of the hematoma capsule was thick and very tough. (Fig. 3). After incising, soft and loose tissues could be seen, without liquid component and segregation. (Fig. 4) Following clearance, it was found that the inner membrane was soft and non-adherent to the brain tissue. It was easy to peel off completely. (Fig. 5, Fig. 6) Following surgery (Fig. 7), the patient's consciousness improved and he was transferred to the intensive care unit for further treatment. Postoperative pathology confirmed CSDH (Fig. 8).

\section{Discussion}

Chronic subdural hematoma is a common condition of the elderly that is often asymptomatic and easy to neglect. There are many treatments, among which burr hole trephination and hematoma is an effective and common approach. ${ }^{1,2}$ ) This technique has minimal effect on OCSHs, especially completely OCSHs. 
OCSH is defined as CSDH with a thick membrane with multiseptations, and encapsulated area with a solid consistency. The incidence of OCSH is low, and its pathogenesis is unclear. This form of CSDH is different from typical CSDH which consist of a fibrous capsule made up of inner and outer membranes filled with bloody fluid. ${ }^{3)}$ It is not known why some CSDHs become organized against hyperfibrinolytic activity known to be the pathogenesis of typical CSDH. The neomembrane in OCSH is similar to granulation tissue. ${ }^{4)}$ Fibrous material slowly accumulates, forming a solid hematoma in which the inner and outer membranes tend to fuse completely. ${ }^{5}$ ) Clinical symptoms of OCSH are variable, ranging from headache, alteration of consciousness, motor weakness, aphasia, to seizures. Mostly, symptoms are minor and there are no neurologic deficits. Ignoring minor symptoms of CSDH can lead to a longstanding hematoma. Prior to this injury, our patient only experienced mild headaches and no other symptoms such as weakness of limbs.

Completely $\mathrm{OCSH}$ are very rare, and only a few reports have been published in literature. ${ }^{6,7)}$ Literature on craniotomy as an initial treatment for OCSH is limited. Baek et al cured one patient through large flap craniotomy and membranectomy which was performed following discovery of a completely organized hematoma via burr hole trephination. ${ }^{6}$ ) Isobe $\mathrm{N}$ et al treated six patients by craniotomy, of which five cases were reoperation for organized hematoma following burr hole trephination. Large flap craniotomy was performed in only two of the six cases. ${ }^{7)}$ Consequently, it is difficult to determine if CSDHs are organized, and the degree of organization pre-operatively.

OCSH are diagnosed with magnetic resonance imaging (MRI) and CT. Our patient was admitted to hospital in emergency after trauma and could not be examined by MRI. OCSH present on CT as mixed density, multiseptated, showing signs of recent hemorrhage, midline shifting, thickened, or calcification of the inner membrane. ${ }^{8)}$ MRI of organized hematomas shows hyperintensity in both T1-T2 weighted images, occasionally hypointense in T1 and hyperintense in T2. All cases display a hypointense web- or net-like structure within the hematoma cavity. $\left.{ }^{9}\right)$ Non-invasive imaging cannot definitely diagnose organized hematomas. We observed similar MRI findings in our patient (Fig. 9, Fig. 10). However, during surgery, it was found that liquid hematoma was the main reason burr hole trephination could solve the situation(Fig. 11).

Following diagnosis of $\mathrm{OCSH}$, removal of both $\mathrm{OCSH}$ and the outer membrane by craniotomy in proportion to hematoma expansion is necessary. ${ }^{8}$ Literature suggests that craniotomy includes small bone window and extended craniotomy. ${ }^{7,10)}$ For small bone window craniotomy, the size of the bone window extends about $4 \mathrm{~cm}$ and only partial membrane excision is feasible. This is suitable for cases with liquid hematoma mainly. There is limited literature on extended craniotomy. In the past, it was believed that craniotomy and removal of the membranes carried high rates of morbidity and mortality. ${ }^{11)}$ These complications result from traction injury in an attempt to remove the membranes adhering tightly to the cortex. Oda et al $^{12)}$ suggested that the inner membrane should be preserved and left intact on the brain surface after removal of only the calcified layer. However, partial inner membrane resection for $\mathrm{OCSH}$ may cause brain herniation. ${ }^{13)}$ 
Recent evidence suggests that large craniotomies for organized subdural hematomas provides a superior and safer opportunity to adequately deal with the hematoma, its membranes, and occasional bleeding. ${ }^{3,9,10)}$ Moreover, extended outer and inner membranectomy is important for expansion of subdural space. ${ }^{9)}$ The outer membrane is related to hematoma enlargement due to repetitive hemorrhages, while the inner membrane is related to liquefaction of the subdural hematoma. ${ }^{9,14)}$

The complications of enlarged craniotomy mainly include tension pneumocephalus, recurring subdural hemorrhage, and postoperative seizures. ${ }^{3)}$ There are few cases of completely OCSH treated by enlarged craniotomy. Balevi $\mathrm{M}$ and Callovini $\mathrm{GM}$ et al have published a large number of cases. However, most of their patients seem to be treated for partially organized hematomas with liquid components still present in the hematomas. Therefore, for completely $\mathrm{OCSH}$, further research and accumulated treatment experience are needed.

\section{Conclusion}

Enlarged craniotomy with membranectomy is a feasible treatment for completely OCSH.

\section{Declarations}

\section{Declaration of conflicting interest}

The authors declare that they have no competing interests.

\section{Statement}

The family of the patient provided informed consent for publication of the case.

\section{Ethics approval and consent to participate}

No need for ethics.

\section{Consent for publication}

All authors agree.

\section{Availability of data and materials}

We declare the data true and reliable. 


\section{Funding}

None

\section{Authors' contributions}

Xiao-Yong Shi collected the patient data and participated in the design and coordination of the study. JinXia Zhang performed the primary writing of the manuscript. Zhu-Xiao Tang collected the patient data.Hu Sun collected the patient data.Zheng Shen conceived the study and participated in its design and coordination.All authors read and approved the final manuscript.

\section{Acknowledgements}

There was no funding source for this manuscript.

\section{References}

1. Lee KS. How to Treat Chronic Subdural Hematoma? Past and Now. J Korean Neurosurg Soc. 2019;62(2):144-152

2. Chan DY, Woo PY, Mak CH, et al. Use of subdural drain for chronic subdural haematoma? A 4-year multi-centre observational study of 302 cases. J Clin Neurosci. 2017;36:27-30

3. Callovini GM, Bolognini A, Callovini G,et al. Primary enlarged craniotomy in organized chronic subdural hematomas. Neurol Med Chir. 2014;54:349-56.

4. Kawano N, Endo M, Saito M, et al. Origin and pathological significance of smooth muscle cells and myofibroblasts in the subdural neomembrane. Neurol Med Chir. 1986; 26:361-368

5. Fujioka M, Okuchi K, Miyamoto S, et al. Bilateral organized chronic subdural haematomas: high field magnetic resonance images and histological considerations. Acta Neurochir . 1994;131:265-269

6. Hong-Gyu Baek and Seong-Hyun Park. Craniotomy and Membranectomy for Treatment of Organized Chronic Subdural Hematoma. Korean J Neurotrauma. 2018;14(2):134-137

7. Isobe N, Sato H, Murakami T, et al. Six cases of organized chronic subdural hematoma. Neurological Surgery. 2008;36(12):1115-20.

8. Asghar M, Adhiyaman V, Greenway MW, et al. Chronic subdural hematoma in the elderly - A north wales experience. J R Soc Med. 2002;95:290-2.

9. Mustafa Balevi. Organized Chronic Subdural Hematomas Treated by Large Craniotomy with Extended Membranectomy as the Initial Treatment. Asian J Neurosurg. 2017;12(4):598-604.

10. Jae-Hong Kim, Dong-Soo Kang, Jung-Hee Kim, et al. Chronic Subdural Hematoma Treated by Small or Large Craniotomy with Membranectomy as the Initial Treatment. J Korean Neurosurg.2011;50:103-108 
11. Hellwig D, Heinze S, Riegel T, et al. Neuroendoscopic treatment of loculated chronic subdural hematoma. Neurosurg Clin N Am.2000;11:525-534

12. Oda S, Shimoda M, Hoshikawa $K$, et al. Organized chronic subdural haematoma with a thick calcified inner membrane successfully treated by surgery: a case report. Tokai J Exp Clin Med. 2010;35:85-88

13. Ito $\mathrm{H}$, Yamamoto $\mathrm{S}$, Komai $\mathrm{T}$, et al. Role of local hyperfibrinolysis in the etiology of chronic subdural hematoma. J Neurosurg. 1976;45:26-31.

14. Araújo Silva DO, Matis GK, Costa LF, et al. Chronic subdural hematomas and the elderly: Surgical results from a series of 125 cases: Old "horses" are not to be shot! Surg Neurol Int. 2012;3:150.

\section{Figures}

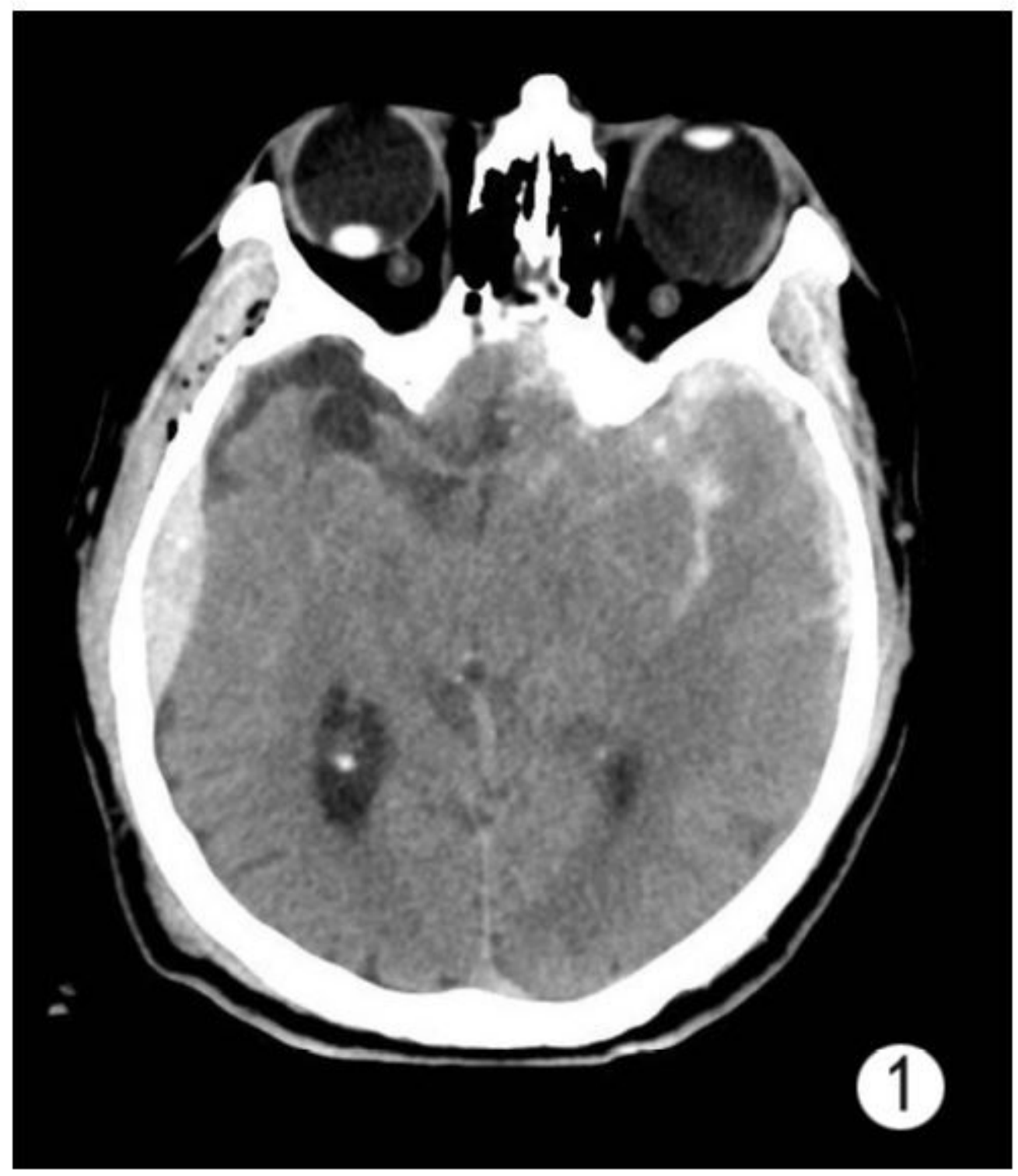

Figure 1 
CT showing right epidural hematoma, left multiple cerebral contusions and lacerations, subarachnoid hemorrhage and acute subdural hematoma.

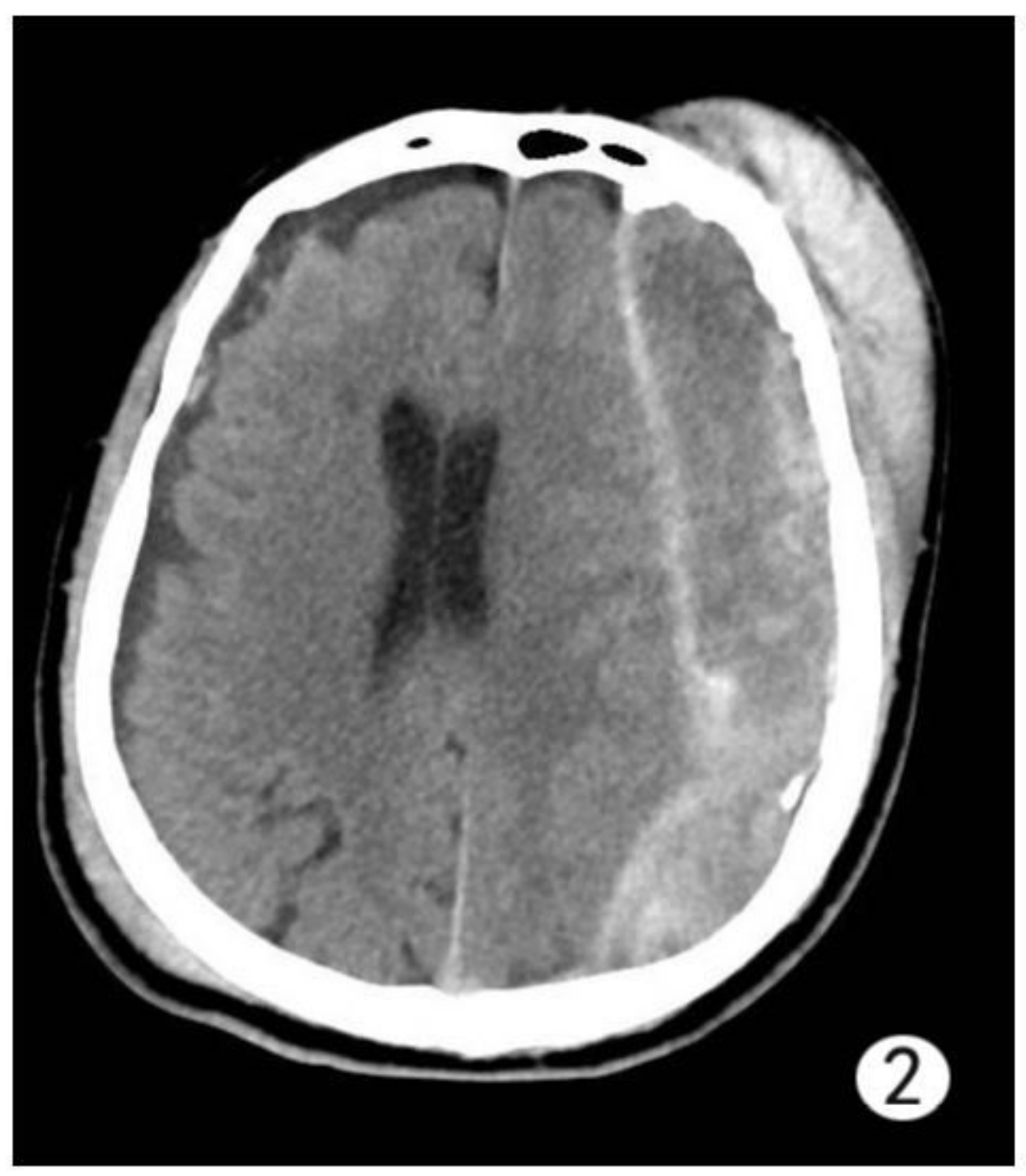

Figure 2

Large hematoma with mixed density on the left. 


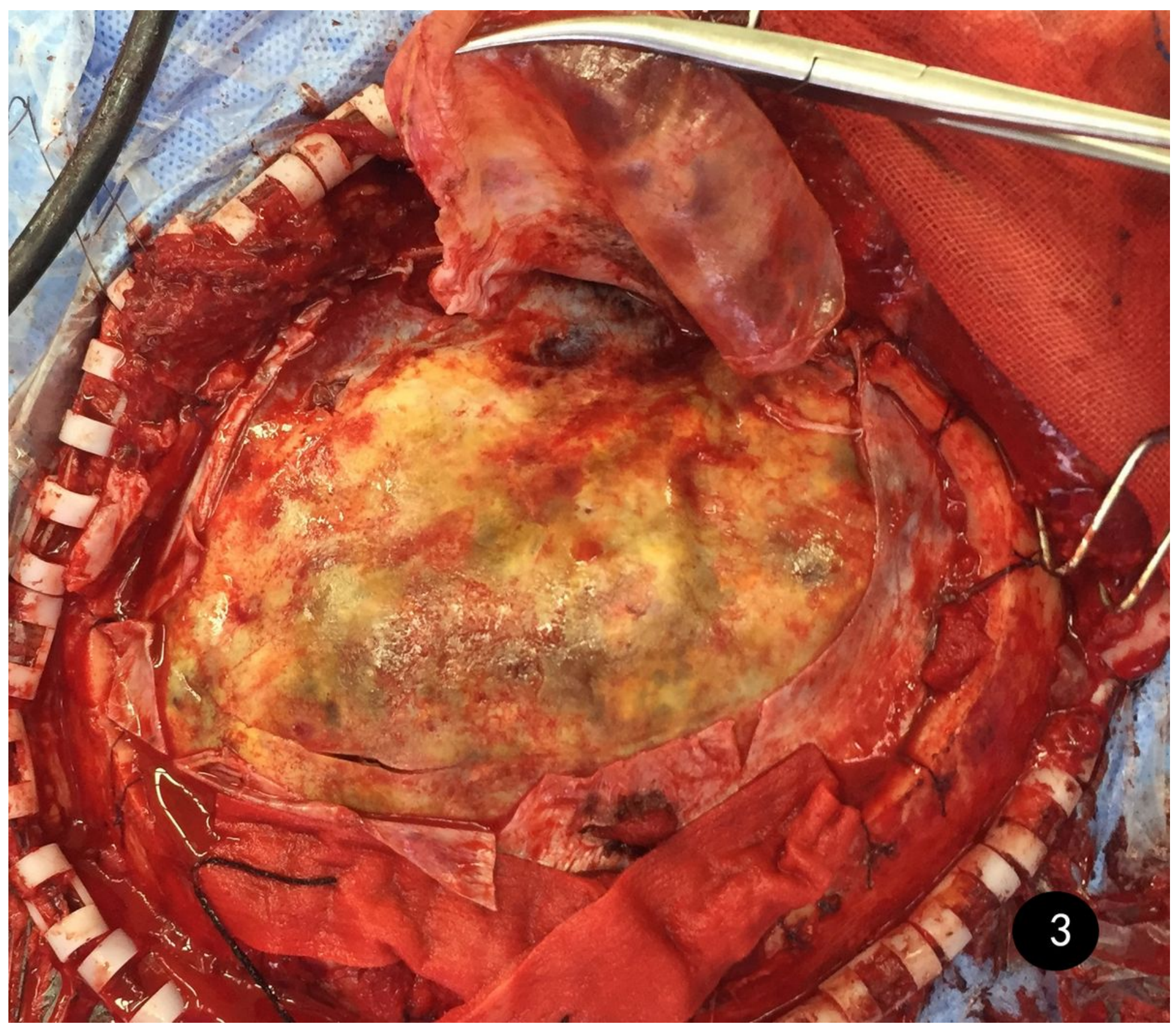

Figure 3

Thick and tough outer wall of the hematoma. 


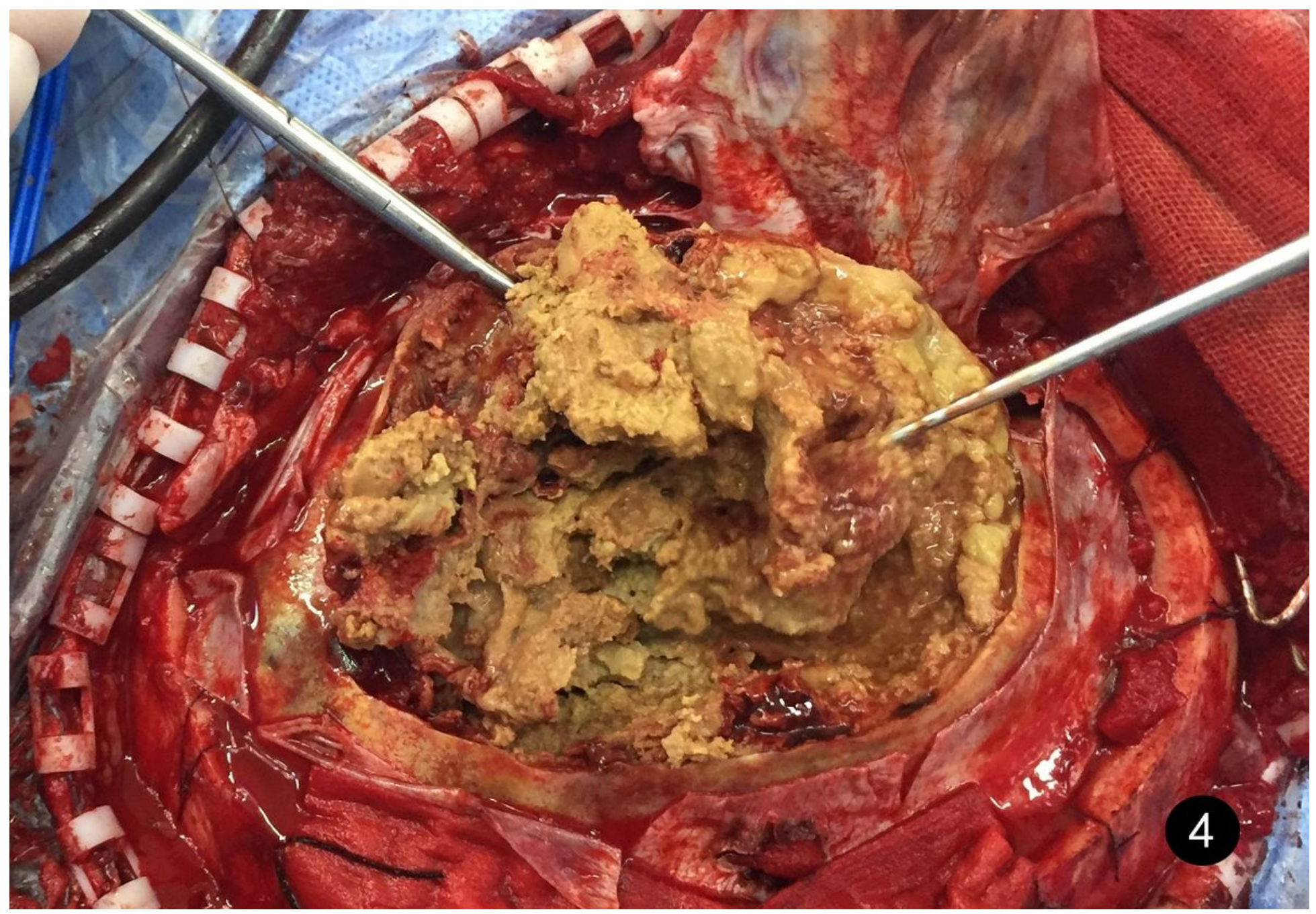

Figure 4

Large amount of soft and loose tissues between membranes. 


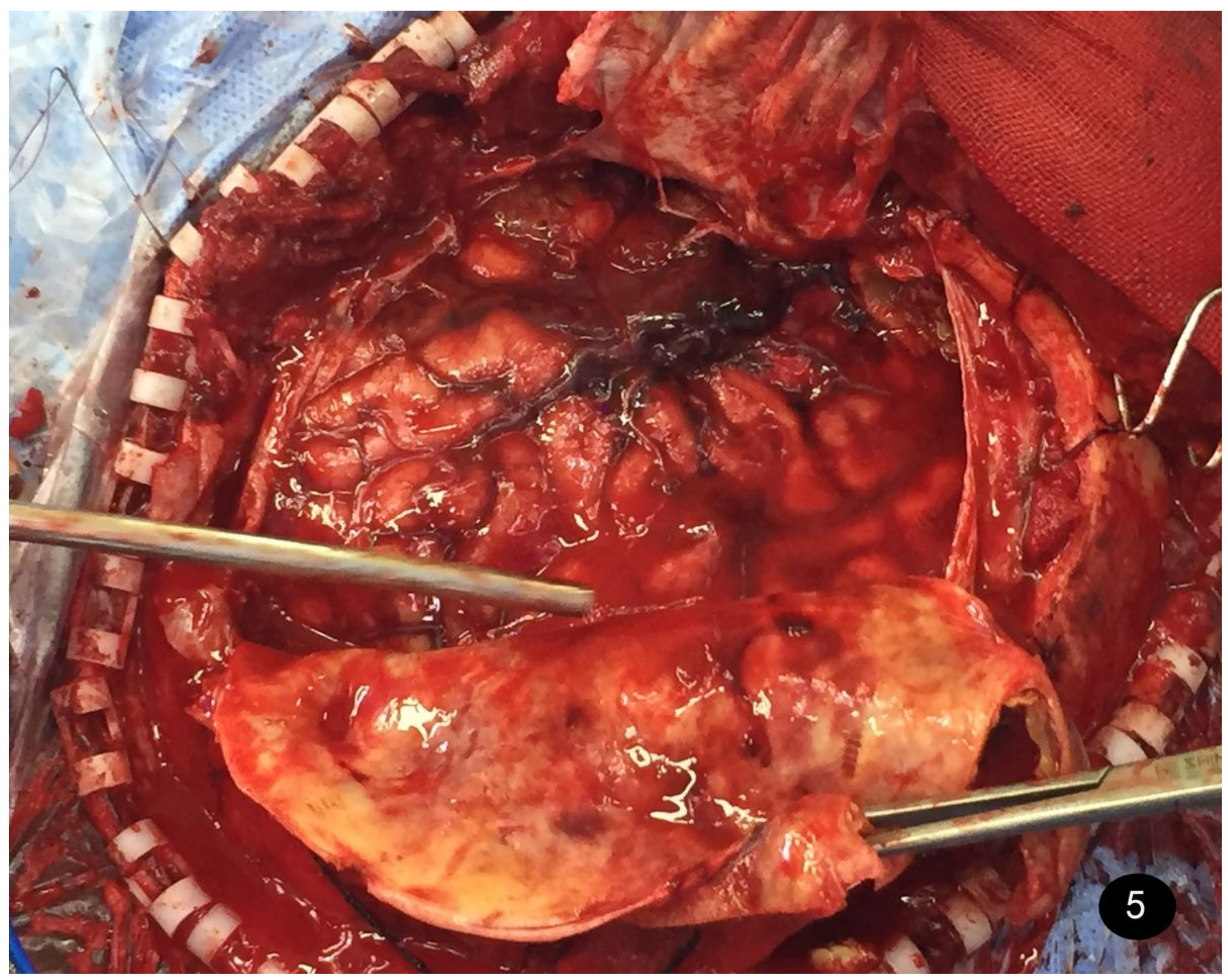

Figure 5

Thick and soft inner membrane. 


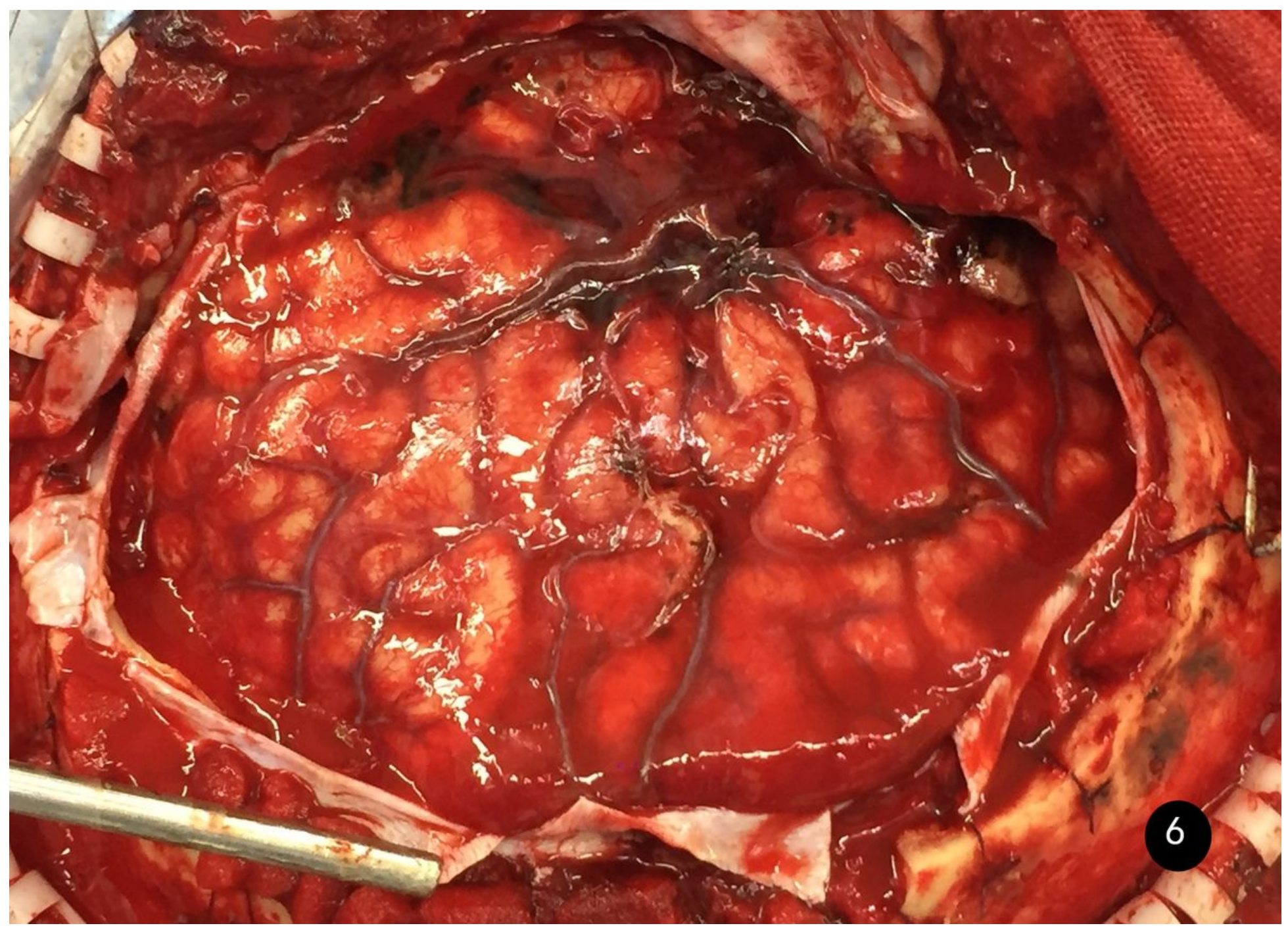

Figure 6

Cerebral surface following removal of OCSH and acute subdural hematoma. 


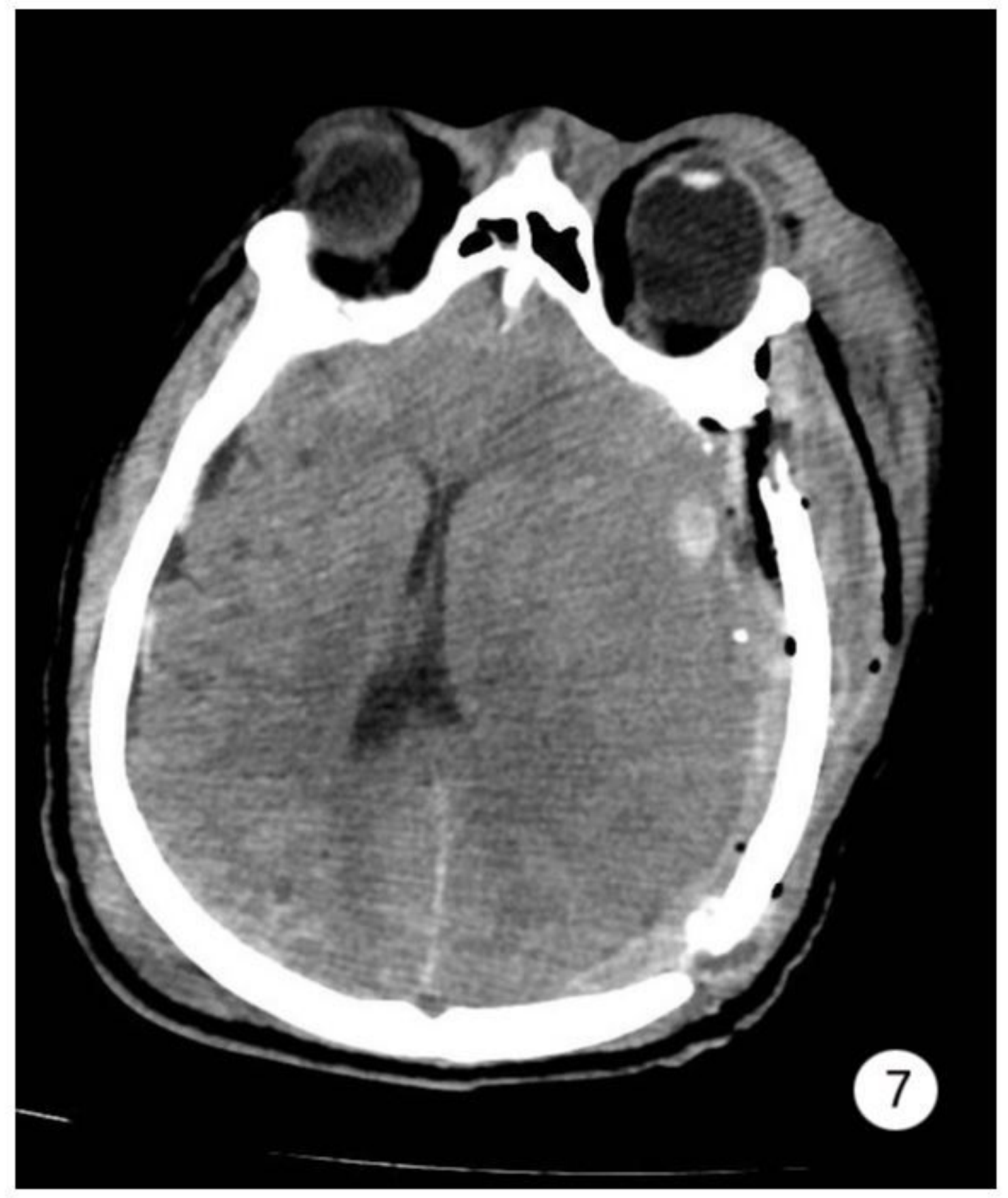

Figure 7

Postoperative CT. 


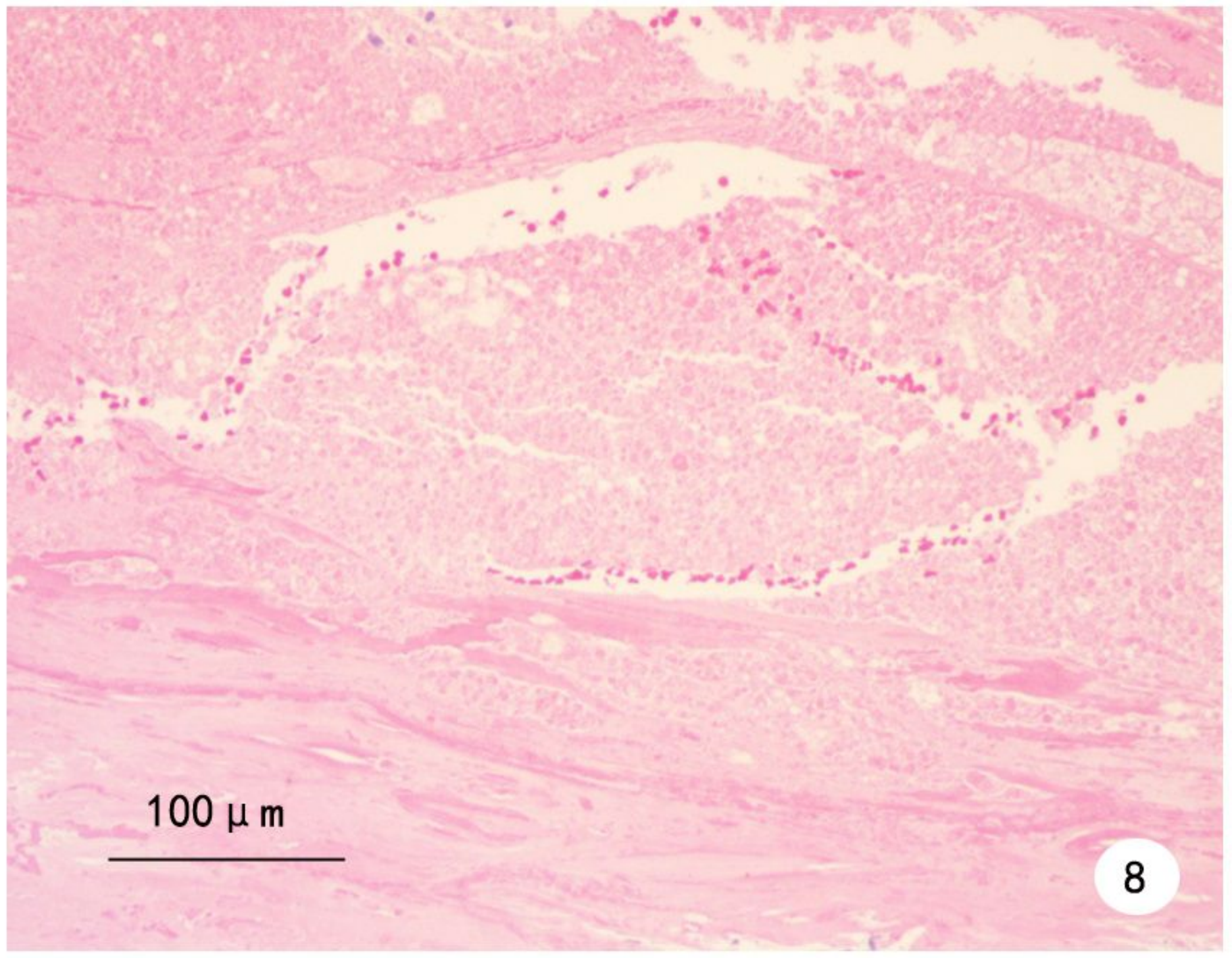

Figure 8

Postoperative pathology showed chronic hematoma(HE stain`200). 


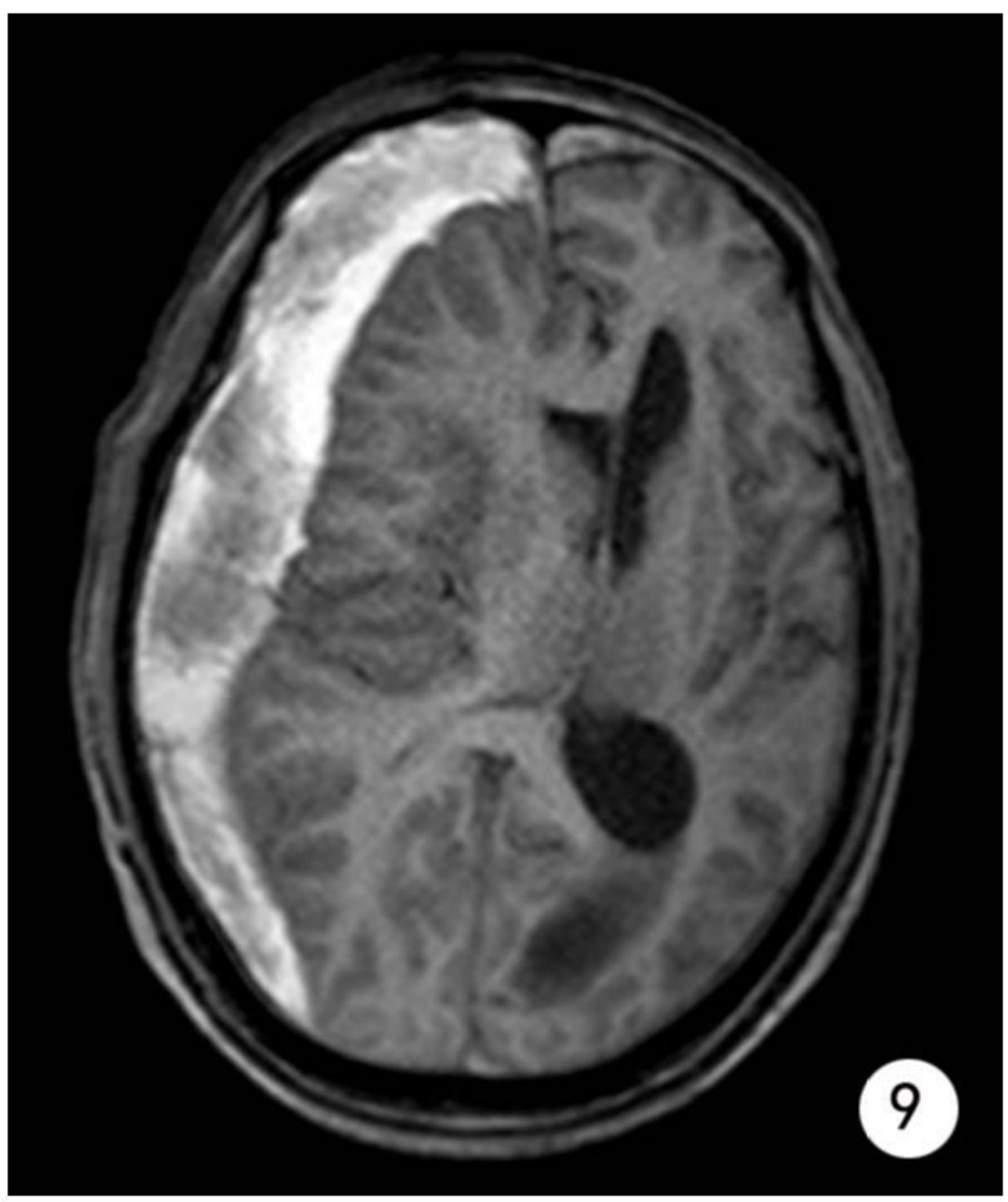

Figure 9

Hypointense web-like structure within the hematoma cavity. 


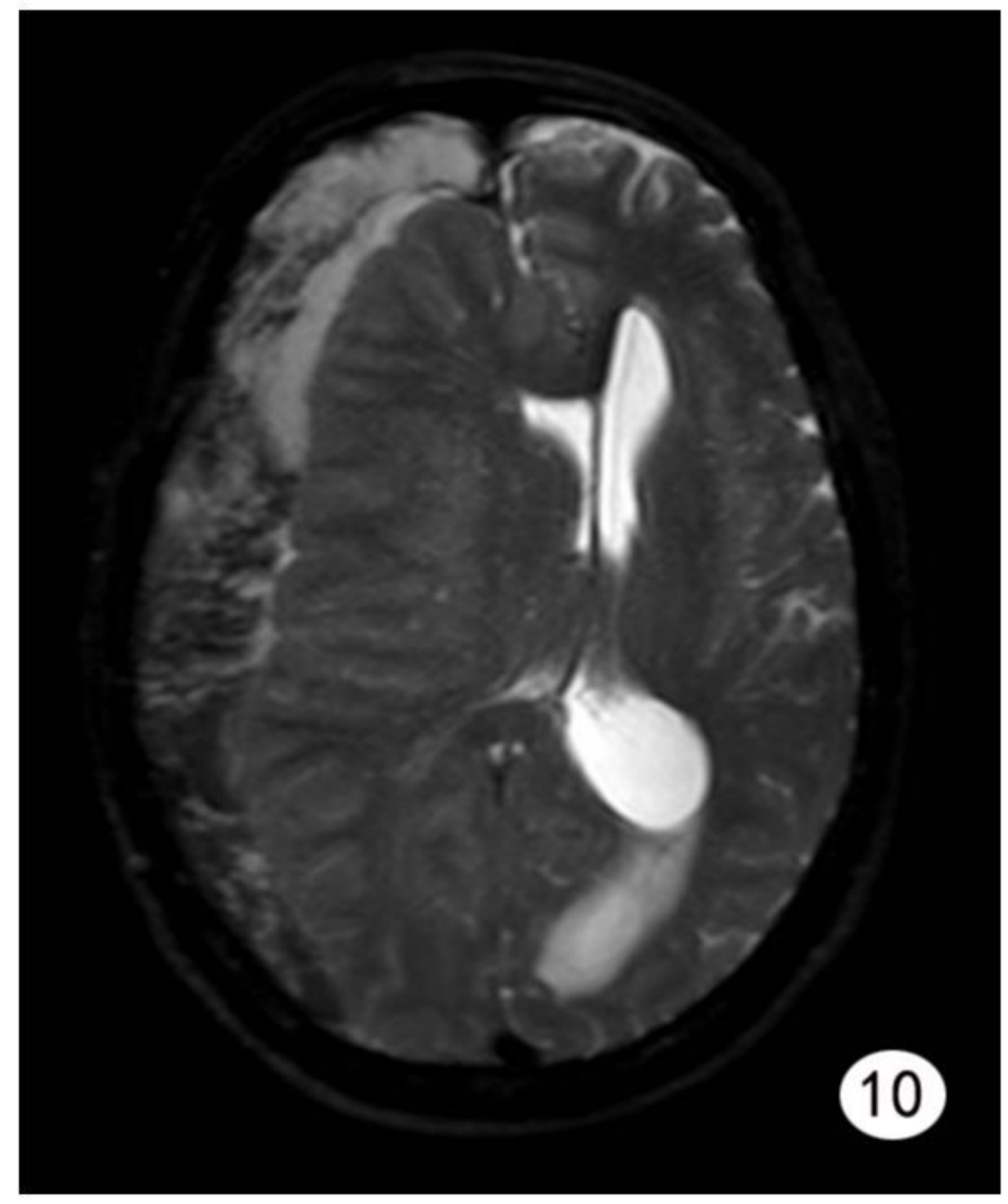

Figure 10

Hypointense web-like structure within the hematoma cavity. 


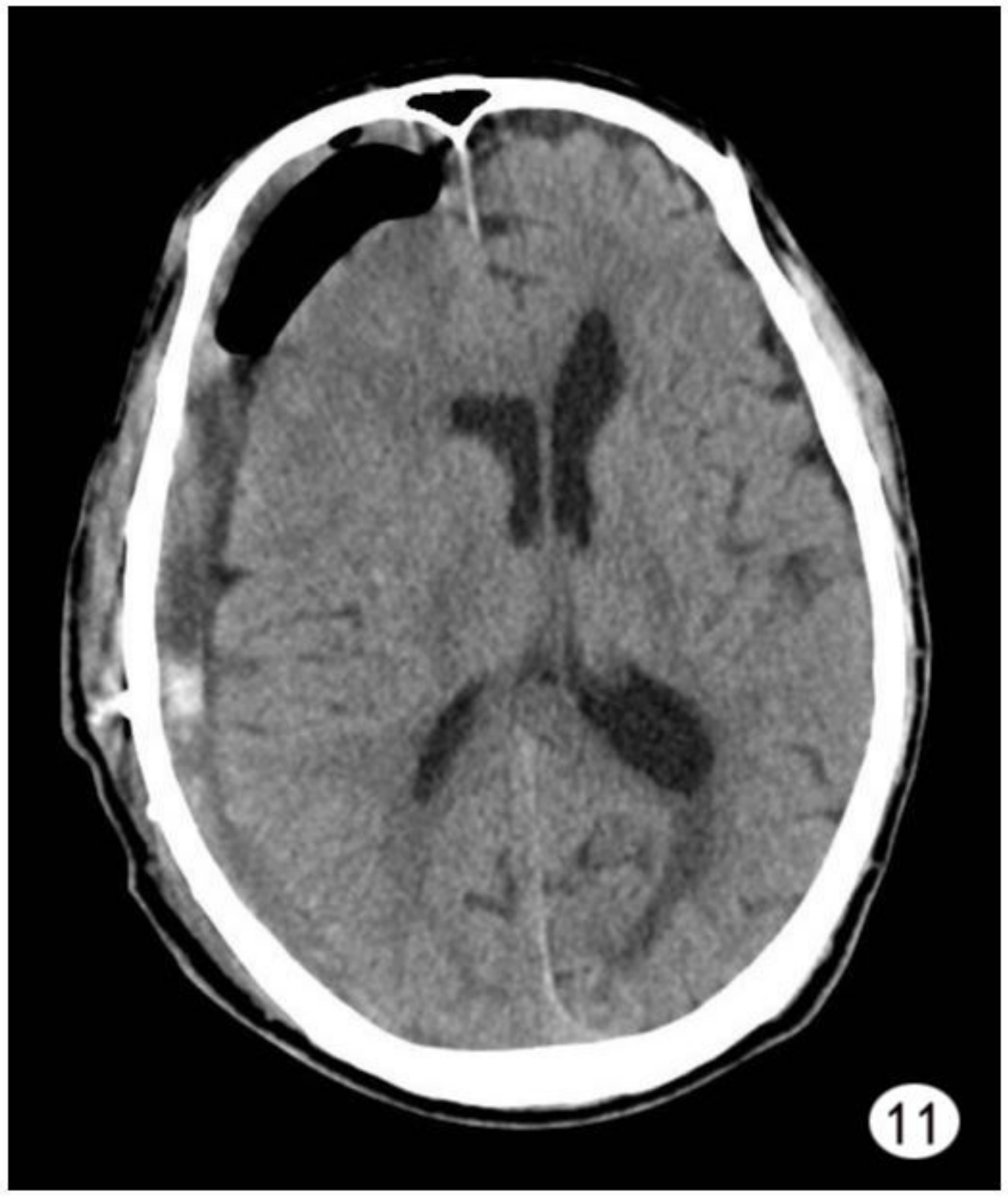

Figure 11

Post-operative CT following burr hole trephination and hematoma drainage. 